Technical Progress Report

Eleventh Quarter

(October 1, 1998 - December 31, 1998)

\title{
AN ADVANCED CONTROL SYSTEM FOR FINE COAL FLOTATION
}

\author{
Principal Investigators \\ G.T. Adel and G. H. Luttrell \\ Department of Mining and Minerals Engineering \\ Virginia Polytechnic Institute and State University \\ Blacksburg, Virginia 24061
}

Contract Number

DE-AC22-95PC95150--11

\author{
DOE Project Officer \\ Carl Maronde \\ United States Department of Energy \\ Federal Energy Technology Center \\ P. O. Box 10940 \\ Pittsburgh, Pennsylvania 15236-0940
}

January 11, 1999

"US/DOE patent clearance is not required prior to the publication of this document." 


\begin{abstract}
A model-based flotation control scheme is being implemented to achieve optimal performance in the handling and treatment of fine coal. The control scheme monitors flotation performance through on-line analysis of tailings ash content. Then, based on an on-line estimate of incremental ash, the pulp level is adjusted using a model-based control algorithm to compensate for feed variations and other process disturbances. Recent developments in sensor technology are being applied for on-line determination of slurry ash content.

During the eleventh quarter of this project, Task 7 (Operation and Testing) was nearly completed through the efforts of J.A. Herbst and Associates, Virginia Tech, and Pittston Coal Company. As a result of this work, a model-based control system has now been installed which can predict incremental ash based on tailings ash content and general plant data, and adjust pulp level accordingly to maintain a target incremental ash. The system has gone through a shakedown period, training has been carried out for plant operators, and the bulk of the control logic testing has been completed with the results of these tests awaiting analysis under Task 8 (System Evaluation). The flotation model has been shown to predict incremental ash quite successfully, implying that this approach may provide the basis for a useful "soft sensor" for on-line incremental ash analysis.
\end{abstract}




\section{TABLE OF CONTENTS}

ABSTRACT

page

TABLE OF CONTENTS $\quad$ iii

LIST OF ILLUSTRATIONS, TABLES AND FIGURES iv

EXECUTIVE SUMMARY $\quad$ v

INTRODUCTION 1

TECHNICAL DISCUSSION 2

Task 1 - Project Planning 2

Task 2 - Sampling and Data Analysis 2

Task 3 - Model Building and Computer Simulation 2

Task 4 - Sensor Testing 2

Task 5 - Sample Analysis and Characterization 2

Task 6 - Equipment Procurement and Installation 2

Task 7 - Operation and Testing 2

Subtask 7.1 - System Start-Up 2

Subtask 7.2 - Operator Training 3

Subtask 7.3 - Data Collection 3

Subtask 7.4 - Control Strategy Evaluation 3

Task 8 - System Evaluation 4

Task 9 - Decommissioning 5

Task 10 - Final Report $\quad 5$

SUMMARY STATUS AND FUTURE WORK 5 


\section{LIST OF ILLUSTRATIONS, TABLES AND FIGURES}

page

Figure 1. Plant test of controllability of incremental ash at Moss \#3. 


\section{EXECUTIVE SUMMARY}

Over the past thirty years, process control has spread from the chemical industry into the fields of mineral and coal processing. Today, process control computers, combined with improved instrumentation, are capable of effective control in many modern flotation circuits. Unfortunately, the classical methods used in most control strategies have severe limitations when used in froth flotation. For example, the nonlinear nature of the flotation process can cause single-input, single-output lines to battle each other in attempts to achieve a given objective. Other problems experienced in classical control schemes include noisy signals from sensors and the inability to measure certain process variables. Factors related to ore type or water chemistry, such as liberation, froth stability, and floatability, are often difficult or impossible to measure.

The purpose of this project is to demonstrate an advanced control system for fine coal flotation. The demonstration is being carried out at an existing coal preparation plant by a team consisting of Virginia Polytechnic Institute and State University (VPI\&SU) as the prime contractor and J.A. Herbst and Associates as a subcontractor. The objectives of this work are: 1) to identify through sampling, analysis, and simulation those variables which can be manipulated to maintain grades, recoveries, and throughput rates at levels set by management; 2) to develop and implement a model-based control strategy that continuously adjusts those variables to maximize revenue subject to various metallurgical, economic, and environmental constraints; and 3) to employ a video-based analyzer for on-line analysis of ash content in fine coal slurries.

Previously, the steady-state and dynamic performance of the flotation bank at the test site (Pittston's Moss No. 3 plant) were characterized as part of Task 2 - Sampling and Data Analysis. The results of this sampling campaign were reported in the Seventh and Eighth Quarterly Technical Progress Reports. The data collected from Task 2 were then used to construct a 
population balance model of the flotation bank at the Moss No. 3 plant (Task 3.1). The details of this work were described in the Eighth Quarterly Technical Progress Report. During the ninth quarter, the population balance model was coded into a flotation circuit simulator which was then used to evaluate control strategies. A control strategy based on maintaining a constant incremental ash in the last cell was deemed most appropriate. Finally, all the necessary equipment and interfaces were installed at the Moss No. 3 test site in order to evaluate the model-based control strategy in conjunction with the video-based ash analyzer. This work was summarized in the Tenth Quarterly Technical Progress Report.

During the past quarter, the model-based control scheme was physically implemented and operator training was carried out. Systematic testing of the control system was also implemented with the results of these tests to be reported in the Twelfth Quarterly Technical Progress Report. Data collected to date indicate that the model behaves in a logical manner and is relatively successful at predicting incremental ash. This latter finding may form the basis for a potential "soft sensor" for on-line incremental ash analysis.

At present, it appears that the project is roughly one or two months behind schedule, but it is still expected that all work can be wrapped up by the end of March, 1999, and the project can be completed on schedule. 


\section{INTRODUCTION}

Over the past thirty years, process control has spread from the chemical industry into the fields of mineral and coal processing. Today, process control computers, combined with improved instrumentation for monitoring process parameters and performance, have demonstrated improved control in many modern flotation plants. Unfortunately, the classical methods used in most control strategies have severe limitations when it comes to control of froth flotation. The nonlinear nature of the flotation process, for example, can cause single-input, single-output control lines to battle each other in attempts to achieve a specific control objective. Other problems experienced in classical control schemes include noisy signals from measuring devices and the inability to measure certain process variables. Furthermore, factors related to ore type or process water chemistry, such as liberation characteristics, froth stability, and floatability, cannot be measured by conventional means.

The purpose of this project is to demonstrate an advanced control system for fine coal flotation at an operating coal preparation plant. The objectives of this work are: 1) to identify through sampling, analysis, and simulation those variables which can be manipulated in the plant to maintain grades, recoveries, and throughput rates at levels set by management; 2) to develop and implement a model-based computer control strategy that continuously adjusts those variables to maximize revenue subject to various metallurgical, economic, and environmental constraints; and 3) to employ a video-based optical analyzer for on-line analysis of ash content in fine coal slurries. The following is a summary of work completed during the eleventh quarter of this project. 


\section{TECHNICAL DISCUSSION}

\section{Task 1 - Project Planning}

Project planning during the past quarter focused primarily on coordinating the efforts of Virginia Tech, J.A. Herbst and Associates, and Pittston Coal Company in carrying out Task 7 (Operation and Testing).

\section{Task 2 - Sampling and Data Analysis}

This task has now been completed.

\section{Task 3 - Model Building and Computer Simulation}

This task has now been completed.

\section{Task 4 - Sensor Testing}

This task has now been completed barring any changes suggested by continued testing at the Moss No. 3 site.

\section{Task 5 - Sample Analysis and Characterization}

Sample analysis is continuing as samples are collected under Task 7. All sample analysis and characterization work is on schedule.

\section{$\underline{\text { Task } 6 \text { - Equipment Procurement and Installation }}$}

This task has now been completed.

\section{$\underline{\text { Task } 7 \text { - Operation and Testing }}$}

Subtask 7.1 - System Start-Up: Due to delays experienced in completing Task 6, actual system start-up began on November 12 and was completed by November 17. The start up went smoothly, however, with no major obstacles being encountered. The ease of start-up reflects the careful preparations, the value of pre-dynamic simulations, and the power of the model-based approach. 
Subtask 7.2 - Operator Training: All personnel responsible for plant operations including the plant manager, the control system manager, and all plant operators were trained on the use of the incremental ash control system. The training required about one eight-hour shift.

Subtask 7.3 - Data Collection: A data collection system was created to allow for automatic monitoring of control system performance. All data acquired and generated by the model and control system are automatically logged to a text file every 3 minutes. An internet connection allows personnel from J.A. Herbst and Associates to remotely access the text file from their headquarters in Hawaii. This latter feature was added to reduce the time required to perform Task 7 and bring the project back on schedule.

Subtask 7.4 - Control Strategy Evaluation: The model-based control strategy described in previous technical progress reports was implemented in the supervisory PC with a model object, a sequential estimator object, and an optimization object embedded in a Visual Basic container. Stated briefly, the object of the control strategy was to maintain a constant incremental ash in the last cell through the manipulation of pulp level. The flotation model was used as a kind of "soft sensor" to estimate incremental ash based on measurements of tailings ash from the video analyzer.

A preliminary test of the strategy was carried out as depicted in Figure 1. Here a series of pulp level setpoint changes were made (63 in., 64 in., 65 in. and 66 in.) over a 90 minute period with collector and frother addition rates remaining constant. The impact on incremental ash, yield, and concentrate ash are calculated from the on-line model and estimator. Confirmation that the predicted changes in concentrate quality occur is obtained by noting that concentrate ash and incremental ash measurements made 
on grab samples at various points during the test period are reasonably close to the model predictions. The concentrate ash is determined in the usual manner, and the incremental ash is determined from the float product obtained from short-term batch flotation tests conducted on the circuit tails. It is significant that the range of incremental ash values obtained from pulp level changes during the test period includes what will ultimately be the overall plant target value of $38 \%$. It is also important to note that this control variable is quite sensitive to changes in the manipulated variable (i.e., pulp level).
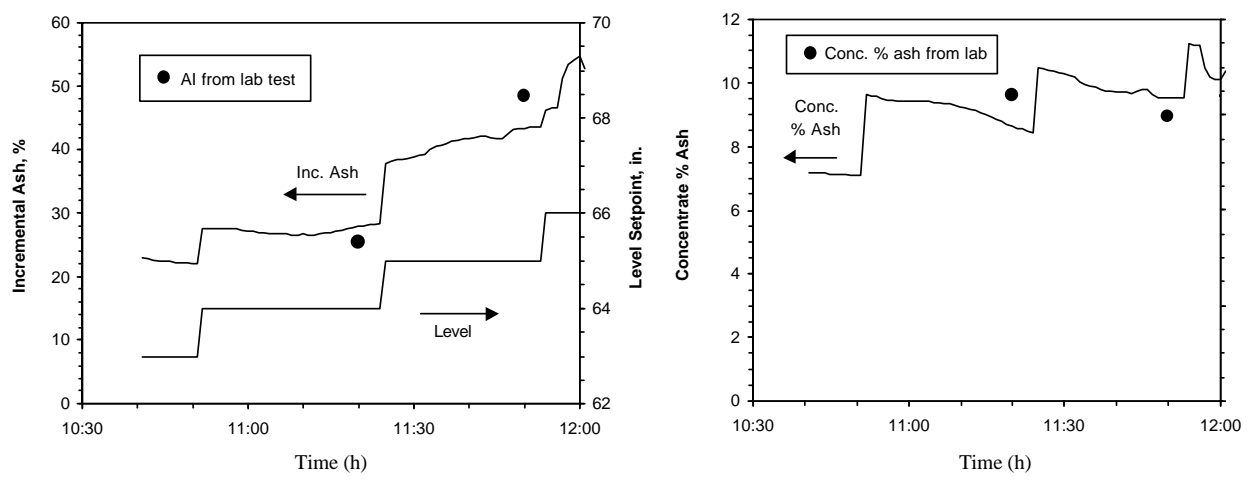

Figure 1. Plant test of controllability of incremental ash at Moss \#3.

During the month of December, an on-off test of the control system was carried out to evaluate its performance. This test procedure involved running the circuit under model-based control for a shift followed by manual control for the next shift. The testing was carried out on a randomized shift basis over a thirty-day period, and the results will be reported in the next quarterly report.

\section{$\underline{\text { Task } 8 \text { - System Evaluation }}$}

This task is currently on-going and there should be results to report in the next quarterly technical progress report. 


\section{Task 9 - Decommissioning}

This task is scheduled to begin in January, 1999.

\section{Task 10 - Final Report}

This task is scheduled to begin in February, 1999.

\section{SUMMARY STATUS AND FUTURE WORK}

The model-based control system is now installed and in operation at Pittston's Moss No. 3 preparation plant. Preliminary tests indicate that the model is performing well and the control system responds as expected. The model appears to make relatively accurate predictions of incremental ash in the last flotation cell of the bank, implying that this approach may be appropriate for creating a "soft sensor" for incremental ash. A series of on-off tests were performed on a shift-by-shift basis to evaluate the performance of the model-based control system. The results of these tests will be included in the next quarterly technical progress report. At this time, Task 7 (Operation and Testing) is nearly complete, and the project is within one or two months of being on schedule. It is still expected that the project will be completed by March 31, 1999, per the original schedule. 